\title{
Long-term effects of telephone follow-up after total knee arthroplasty
}

\author{
Kirsten Szöts ${ }^{1}$, Hanne Konradsen*2, Soren Solgaard ${ }^{1}$, Birte Oestergaard ${ }^{3}$ \\ ${ }^{1}$ Department of Orthopaedic Surgery, Gentofte University Hospital, Denmark \\ ${ }^{2}$ Research Unit, Gentofte University Hospital, Denmark \\ ${ }^{3}$ Institute of Clinical Research, Faculty of Health Sciences, University of Southern Denmark, Denmark
}

Received: January 26, 2016

DOI: $10.5430 /$ jnep.v6n7p151
Accepted: March 28, 2016

Online Published: April 14, 2016

\begin{abstract}
Objective: To evaluate the effects of structured nurse-managed telephone follow-up one year after discharge from hospital following total knee arthroplasty.

Method: A randomized parallel group design was used. Primary outcome was physical function, measured by the Western Ontario and McMaster Universities Osteoartharitis (Womac) Index. Secondary outcomes were pain and stiffness scores in the Womac Index, change in health-related quality of life, measured by the Medical Outcomes Study Short Form (SF-36), and changes in self-efficacy, measured by the General Self-Efficacy Scale.

Result: In total 108 patients (mean age 68 years, SD 8.9) were included. A positive tendency, but not significant, were detected in several dimensions of health status, health related quality of life and self-efficacy in favour of nurse-managed Telephone follow-up in comparison with treatment as usual.

Conclusion: Knowledge of the effect of telephone follow-up after discharge following total knee arthroplasty (TKA) is needed when clinical practice decides on whether to implement this way of organizing the patient trajectory.
\end{abstract}

Key Words: Knee arthroplasty, Nursing, Telephone follow-up

\section{INTRODUCTION}

Due to shortened hospitalization, patients are now becoming responsible for their recovery at a very early stage. Hereby the time available to educate patients adequately to be able to manage the recovery period after discharge is restricted. After discharge from hospital following total knee arthroplasty (TKA), research has illustrated a range of health-related problems that patients may experience, ${ }^{[1]}$ and studies have revealed that these patients need guidance from health professionals in the early rehabilitation period. ${ }^{[2]}$

Telephone follow-up (TFU) is considered to be a useful means of providing health education and counselling. ${ }^{[3]}$ The present study evaluated the effects of structured nursemanaged TFU one year after discharge from the hospital following TKA. The short-term effects have been published previously. ${ }^{[4]}$

\section{METHOD}

The study was designed as a randomized clinical trial. The protocol was published earlier. ${ }^{[5]}$

Participants were allocated according to a web based randomization system (1:1), all received conventional treatment

*Correspondence: Hanne Konradsen; Email: Hanne.Konradsen@regionh.dk; Address: Galionsvej 1c, st, 1437 Copenhagen K, Denmark. 
and furthermore those in the intervention group received structured TFU four and fourteen days after discharge. ${ }^{[5]}$

The effect of the intervention was measure on physical function by the Womac Index. Secondary outcomes were pain and stiffness scores, change in health-related quality of life, and changes in self-efficacy.

Patients were recruited from the Orthopaedic Surgical Department of a medium-sized university hospital in Denmark. Patients were included consecutively in the trial if they had undergone primary first-time TKA, were aged $>18$ years, had followed a conventional course of treatment, were discharged $\leq 4$ days post-surgery, were able to read and understand Danish, and had signed an informed consent form. Patients were excluded if they had previously undergone total hip arthroplasty.

Calculation of sample size was based on the smallest clinically-relevant improvement in physical function according to the Womac Index. Assuming a mean difference of a minimum of twelve points in difference between the two groups, 48 patients were required in each group, based on a standard deviation estimated at 18 points, alpha $=0.05$, and a power of $90 \%$. We anticipated that $20 \%$ of included patients would drop-out, therefor 58 patients were needed in each group. The trial was conducted without blinding, with the participants being informed of the results of the randomization immediately before discharge. ${ }^{[5]}$

All patients included in the trial followed conventional treatment of TKA: i.e. attending a multidisciplinary pre-surgery seminar when admitted to hospital the evening before or on the day of surgery, discharge scheduled two-three days postsurgery and furthermore post-hospitalization physiotherapy, removal of stitches and outpatient consultation with the surgeon. In the intervention group 3 patients received home care nursing, in the control group no patient did.

Participants allocated to the intervention group received TFU four and fourteen days after discharge. The first author, an experienced orthopaedic nurse, conducted all TFUs. The TFU was structured according to the nursing status as defined by the VIPS (well-being, integrity, prophylaxis, safety) model and supplemented with other issues relevant to patients after TKA ${ }^{[5]}$ regarding observation of the wound, how to best manage medical treatment for pain and how to exercise as recommended.

Data for outcome measures were collected by self-admini- stered questionnaires at baseline (three days after discharge from hospital), and six and twelve months post-surgery. The following questionnaires were used:

The Womac Index LK 3.1 including three subscales: pain, stiffness and physical function. Responses were transformed to scores from 0 to 100 (more pain, stiffness, and functional limitations).

The Medical Outcomes Study Short Form (SF-36v2) including eight subscales: physical function, role physical, bodily pain, general health, vitality, social functioning, role, emotional and mental health. Responses on each scale were transformed to a score from 0 to 100 (100 being the best).

The General Self-Efficacy Scale, which is a unidimensional scale with a score between 10 and 40 (highest level of selfefficacy).

The regional Danish Data Protection Agency approved the trial. The trial was submitted to The Regional Committee on Health Research Ethics, and an approval was not required. The trial followed the recommendation from the Declaration of Helsinki.

\section{RESUltS}

Between January and September 2013, 117 patients with a mean age of 68 years (SD 8.9) were included $(n=59$ in the TFU group, $n=58$ in the control group). In total nine patients were lost to follow-up before baseline data were collected (Six patients withdraw consent and three patients never returned questionnaires), and data from 108 patients (54 in each group) were included in the analysis. Two patients (both in the control group) were lost to follow-up after baseline data were collected ( $\mathrm{n}=1$ died, $\mathrm{n}=1$ withdrew).

No significant difference was identified in patient characteristics (age, gender, ASA class, length of stay, education level, occupational and civil status, home care, home nursing, and physical inhibition not due to TKA) or in baseline scores between the TFU and control groups.

No significant effects of TFU on the primary outcome physical function were identified six or twelve months after TKA. A positive tendency in favour of the intervention group was identified in several dimensions of health status, healthrelated quality of life, and self-efficacy (see Table 1). Imputation of missing scores based on last observation carried forward, mean values, and worst/best scores did not lead to any significant results. 
Table 1. Difference in scores in Womac Index subscales \& SF-36 from baseline to 6 and 12 months, and in General Self-efficacy Scale from baseline to 6 months after total knee arthroplasty in and between intervention and control group

\begin{tabular}{|c|c|c|c|c|c|c|c|c|}
\hline & \multicolumn{4}{|c|}{ Difference from baseline to 6 months } & \multicolumn{4}{|c|}{ Difference from baseline to 12 months } \\
\hline & $\begin{array}{l}\text { Interven- } \\
\text { tion Group }\end{array}$ & $\begin{array}{l}\text { Control } \\
\text { group }\end{array}$ & $\begin{array}{l}\text { Difference } \\
\text { between } \\
\text { groups }\end{array}$ & $p$ & $\begin{array}{l}\text { Intervention } \\
\text { group }\end{array}$ & $\begin{array}{l}\text { Control } \\
\text { group }\end{array}$ & $\begin{array}{l}\text { Difference } \\
\text { between } \\
\text { groups }\end{array}$ & $p$ \\
\hline & \multicolumn{3}{|c|}{ Mean (CI 95\%) } & & \multicolumn{3}{|c|}{ Mean (CI 95\%) } & \\
\hline \multicolumn{9}{|l|}{ WOMAC } \\
\hline $\begin{array}{l}\text { Physical } \\
\text { Function }\end{array}$ & $\begin{array}{l}-29.8 \\
(-34.5 ;-25.1)\end{array}$ & $\begin{array}{l}-29.3 \\
(-34.6 ;-24.0)\end{array}$ & $\begin{array}{l}-0.5 \\
(-7.5 ; 6.5)\end{array}$ & .887 & $\begin{array}{l}-32.6 \\
-37.1 ;-28.1)\end{array}$ & $\begin{array}{l}-32.3 \\
(-38.2 ;-26.3)\end{array}$ & $\begin{array}{l}-0.3 \\
(-7.6 ; 6.9)\end{array}$ & .929 \\
\hline Pain & $\begin{array}{l}-25.3 \\
(-30.0 ;-20.6)\end{array}$ & $\begin{array}{l}-24.3 \\
(-29.7 ;-18.9)\end{array}$ & $\begin{array}{l}-1.0 \\
(-8.0 ; 6.1)\end{array}$ & .785 & $\begin{array}{l}-25.9 \\
(-30.8 ;-21.0)\end{array}$ & $\begin{array}{l}-29.5 \\
(-35.2 ;-23.8)\end{array}$ & $\begin{array}{l}3.6 \\
(-3.7 ; 11.0)\end{array}$ & .329 \\
\hline Stiffness & $\begin{array}{l}-32.0 \\
(-38.7 ;-25.3)\end{array}$ & $\begin{array}{l}-23.7 \\
(-30.9 ;-16.4)\end{array}$ & $\begin{array}{l}-8.3 \\
(-18.1 ; 1.4)\end{array}$ & .093 & $\begin{array}{l}-33.7 \\
(-39.9 ;-27.5)\end{array}$ & $\begin{array}{l}-32.6 \\
(-40.1 ;-25.1)\end{array}$ & $\begin{array}{l}1.1 \\
(-10.6 ; 8.5)\end{array}$ & .825 \\
\hline \multicolumn{9}{|l|}{ SF-36 } \\
\hline$P F$ & $\begin{array}{l}38.5 \\
(34.3 ; 54.6)\end{array}$ & $\begin{array}{l}29.4 \\
(20.4 ; 38.3)\end{array}$ & $\begin{array}{l}9.1 \\
(-2.0 ; 20.2)\end{array}$ & .107 & $\begin{array}{l}40.7 \\
(32.7 ; 48.7)\end{array}$ & $\begin{array}{l}34.0 \\
(25.0 ; 43.1)\end{array}$ & $\begin{array}{l}6.7 \\
(-5.2 ; 18.6) \\
10.0^{*} \\
(-5.0 ; 20.0)\end{array}$ & $\begin{array}{l}.265 \\
.199\end{array}$ \\
\hline$R P$ & $\begin{array}{l}44.5 \\
(34.3 ; 54.6)\end{array}$ & $\begin{array}{l}40.8 \\
(30.7 ; 50.8)\end{array}$ & $\begin{array}{l}3.7 \\
(-10.5 ; 17.8)\end{array}$ & .607 & $\begin{array}{l}45.7 \\
(37.1 ; 54.3)\end{array}$ & $\begin{array}{l}44.3 \\
(33.2 ; 55.5)\end{array}$ & $\begin{array}{l}1.3 \\
(-12.5 ; 15.1) \\
0.0^{*} \\
(-12.5 ; 12.5)\end{array}$ & $\begin{array}{l}.849 \\
.9405\end{array}$ \\
\hline$B P$ & $\begin{array}{l}39.2 \\
(31.4 ; 47.1)\end{array}$ & $\begin{array}{l}34.0 \\
(26.5 ; 41.6)\end{array}$ & $\begin{array}{l}5.2 \\
(-10.5 ; 17.8)\end{array}$ & .340 & $\begin{array}{l}42.4 \\
(35.4 ; 49.5)\end{array}$ & $\begin{array}{l}43.5 \\
(35.8 ; 51.2)\end{array}$ & $\begin{array}{l}-1.1 \\
(-11.3 ; 9.2) \\
0.0^{*} \\
(-11.0 ; 10.0)\end{array}$ & $\begin{array}{l}.838 \\
.946\end{array}$ \\
\hline$G H$ & $\begin{array}{l}4.1 \\
(-.03 ; 8.4)\end{array}$ & $\begin{array}{l}-1.8 \\
(-7.0 ; 3.5)\end{array}$ & $\begin{array}{l}5.8 \\
(-0.8 ; 12.5) \\
5.0^{*} \\
(0 ; 12)\end{array}$ & $\begin{array}{l}.086 \\
.108\end{array}$ & $\begin{array}{l}4.3 \\
(0.0 ; 8.6)\end{array}$ & $\begin{array}{l}1.1 \\
(-4.8 ; 7.1)\end{array}$ & $\begin{array}{l}3.2 \\
(-4.0 ; 10.3) \\
5.0^{*} \\
(-5.0 ; 10.0)\end{array}$ & $\begin{array}{l}.379 \\
.265\end{array}$ \\
\hline$V T$ & $\begin{array}{l}17.9 \\
(10.6 ; 25.1)\end{array}$ & $\begin{array}{l}24.6 \\
(18.7 ; 30.5)\end{array}$ & $\begin{array}{l}-6.7 \\
(-16.0 ; 2.6) \\
-6.3^{*} \\
(-18.3 ; 0)\end{array}$ & $\begin{array}{l}.157 \\
.117\end{array}$ & $\begin{array}{l}23.5 \\
(16.4 ; 30.6)\end{array}$ & $\begin{array}{l}24.8 \\
(18.4 ; 31.2)\end{array}$ & $\begin{array}{l}-1.3 \\
(-10.8 ; 8.2) \\
0.0^{*} \\
(-12.5 ; 6.25)\end{array}$ & $\begin{array}{l}.783 \\
.879\end{array}$ \\
\hline$S F$ & $\begin{array}{l}24.3 \\
(15.7 ; 32.8)\end{array}$ & $\begin{array}{l}14.3 \\
(5.6 ; 23.1)\end{array}$ & $\begin{array}{l}10.0 \\
(-2.2 ; 22.0)\end{array}$ & .107 & $\begin{array}{l}23.5 \\
(14.9 ; 32.1)\end{array}$ & $\begin{array}{l}14.6 \\
(7.1 ; 22.2)\end{array}$ & $\begin{array}{l}8.9 \\
(-2.5 ; 20.3)\end{array}$ & .125 \\
\hline$R E$ & $\begin{array}{l}23.3 \\
(14.1 ; 32.6)\end{array}$ & $\begin{array}{l}23.1 \\
(14.3 ; 32.0)\end{array}$ & $\begin{array}{l}0.2 \\
(-12.5 ; 12.9) \\
0.0 \\
(-8.3 ; 8.3)\end{array}$ & $\begin{array}{l}.977 \\
.994\end{array}$ & $\begin{array}{l}24.7 \\
(16.5 ; 32.8)\end{array}$ & $\begin{array}{l}22.2 \\
(12.5 ; 32.0)\end{array}$ & $\begin{array}{l}2.4 \\
(-10.0 ; 14.9)\end{array}$ & .698 \\
\hline$M H$ & $\begin{array}{l}9.6 \\
(3.8 ; 15.4)\end{array}$ & $\begin{array}{l}12.4 \\
(6.7 ; 18.2)\end{array}$ & $\begin{array}{l}-2.8 \\
(-10.9 ; 5.3) \\
-2.5^{*} \\
(-10.0 ; 5.0)\end{array}$ & $\begin{array}{l}.491 \\
.5731\end{array}$ & $\begin{array}{l}15.6 \\
(11.4 ; 19.8)\end{array}$ & $\begin{array}{l}12.6 \\
(7.3 ; 17.9)\end{array}$ & $\begin{array}{l}3.0 \\
(-3.7 ; 9.7) \\
5.0^{*} \\
(-5.0 ; 10.0)\end{array}$ & $\begin{array}{l}.3741 \\
.4205\end{array}$ \\
\hline $\begin{array}{l}\text { Self- } \\
\text { Efficacy }\end{array}$ & $\begin{array}{l}2.3 \\
(0.9 ; 3.7)\end{array}$ & $\begin{array}{l}0.9 \\
(-0.6 ; 2.4)\end{array}$ & $\begin{array}{l}1.4 \\
(-0.6 ; 3.4) \\
2.0^{*} \\
(0.0 ; 3.0)\end{array}$ & $\begin{array}{l}.177 \\
.124\end{array}$ & & & & \\
\hline
\end{tabular}

Note. $P$-values and $95 \%$ confidence intervals are result of parametric tests and supplemented the results of the corresponding non-parametric test for not normally distributed data (indicated in italics). ${ }^{*}$ Median and Hodges-Lehman CI 95\%. PF = Physical function, RP = Role physical, BP = Bodily pain, GH = General health, VT = Vitality, SF = Social functioning, RE = Role emotional, and $\mathrm{MH}=$ Mental health.

\section{DiscuSSION}

This is the first randomized trial evaluating the long-term effect of structured TFU following total knee replacement.

Published by Sciedu Press
No significant difference was found between the two groups in neither primary nor secondary outcomes. Short-term effect in relation to patients who have undergone orthopaedic 
surgery has shown divergent results. A study which included patients after total hip replacement showed improved hip joint function after six months. ${ }^{[6]}$ Patients undergoing orthopaedic surgery in general did not report fewer health problems after three weeks, but an increase in health care contacts. ${ }^{[7]}$ Clari et al however, found a significant reduction in all post discharge problems (anxiety, bowel management, eating, bathing and dressing) except mobilisation and pain after two weeks. ${ }^{[8]}$ Following the patient trajectory, it has been shown that patients after total hip replacement benefit from TFU in that the time they need to reach habitual level in health status might be reduced. ${ }^{[9]}$

The sample-size calculation was based on achieving a mean difference of minimum 12 points in physical function score in favour of the intervention group. The risk of type 2 error is important, and a more modest reduction cannot be excluded, but detection of a small difference would need to be investigated in a larger randomized trial. The detection of such a small difference as 29.8 versus 29.3 would require approximately 3,500 patients if a type 2 error of $20 \%$ is accepted. Therefore, the long-term improvement in pain, stiffness and several scores on health-related quality of life and self-efficacy in favour of TFU is noteworthy. It can be discussed whether these outcomes better captures the essence of nursing interventions such as TFU instead of using a relative hard outcome measure such as physical function. In comparison, when Hoerdam et al. ${ }^{[9]}$ investigated the effect

\section{REFERENCES}

[1] Westby MD, Backman CL. Patient and health professional views on rehabilitation practices and outcomes following total hip and knee arthroplasty for osteoarthritis: a focus group study. BMC Health Services Research. 2010; 10: 119. PMid:20459834. http: //dx.doi.org/10.1186/1472-6963-10-119

[2] Barksdale P, Backer J. Health-related stressors experienced by patients who underwent total knee replacement seven days after being discharged home. Orthopaedic nursing/National Association of Orthopaedic Nurses. 2005; 24(5): 336-342. http://dx.doi .org/10. 1097/00006416-200509000-00009

[3] Mistiaen P, Poot E. Telephone follow-up, initiated by a hospitalbased health professional, for post discharge problems in patients discharged from hospital to home. Cochrane Database of Systematic Reviews. 2006; 4: CD004510.

[4] Szöts K, Konradsen H, Solgaard S, et al. Telephone Follow-up by Nurse after Total Knee Arthroplasty: Results of a Randomized Clinical Trial. Accepted for publication Orthopaedic Nursing. 2016.

[5] Szöts K, Konradsen H, Solgaard S, et al. Telephone follow-up by nurse following total knee arthroplasty - a randomized clinical trial
TFU on patients undergoing total hip replacement they found a significant difference in favour of the intervention in three out of eight SF-36 subscales at 3 months follow-up. Hence, there is a need for larger multi-center trials in order to verify whether TFU can improve pain, stiffness, quality of life and self-efficacy in in patients undergoing TKA.

TFU is a relatively simple and low-cost intervention to implement in clinical practice. Further studies are also needed in order to explore if all patients would benefit from the telephone calls in other areas such as patients feeling safe and informed.

\section{Conclusion}

We were not able to identify a long-term effect of TFU on physical function scores compared to conventional treatment. A positive tendency in favour of the intervention group was identified in scores in several dimensions of health status, health-related quality of life, and self-efficacy. However, larger properly powered multi-center trials are needed to further investigate the short-term and long-term effect of TFU on these outcomes, before final conclusions can be drawn. The results of this study add knowledge that is relevant for decisions relating to the implementation of TFU into clinical practice, but factors such as short-term effect, cost, and quality of aftercare in the patient view must also be considered.

\section{CONFliCtS OF INTEREST Disclosure}

The authors declare that there are no competing interests.
BMC Nursing. 2014; 13(14); eCollection.

[6] Li LL, Gan YY, Zhang LN, et al. The effect of post-discharge telephone intervention on rehabilitation following total hip replacement surgery. International Journal of Nursing Science. 2014: 207-211. http://dx.doi.org/10.1016/j.ijnss.2014.05.005

[7] Hodgins MJ, Ouellet L, Pond S, et al. Effect of telephone follow-up on surgical orthopedic recovery. Applied Nursing Research. 2008; 21: 218-226. PMid:18995164. http://dx.doi.org/10.1016/j .apnr.2007.01.008

[8] Clari M, Frigerio S, Ricceri F, et al. Follow-up telephone calls to patients after undergoing orthopaedic surgery: double-blind, randomised controlled trial of efficacy. Journal of Clinical Nursing. 2015; 24: 2736-2744. PMid:25705815. http://dx.doi.org/10. $1111 /$ jocn. 12795

[9] Hoerdam B, Sabroe S, Pedersen PU, et al. Nursing intervention by telephone interviews of patients aged over 65 years after total hip replacement improves health status: a randomised clinical trial. Scandinavian Journal of Caring Sciences. 2010; 24: 94-100. PMid:19422632. http://dx.doi.org/10.1111/j.1471-6712. 2009.00691.x 